\title{
Advances in Research on Epichloë endophytes in Chinese Native Grasses
}

\section{Hui Song, Zhibiao Nan*, Qiuyan Song, Chao Xia, Xiuzhang Li, Xiang Yao, Wenbo Xu, Yu Kuang, Pei Tian and Qingping Zhang}

State Key Laboratory of Grassland Agro-Ecosystems, College of Pastoral Agriculture Science and Technology, Lanzhou University, Lanzhou, China

Epichloë fungal endophytes are broadly found in cool-season grasses. The symbiosis between these grasses and Epichloë may improve the abiotic and biotic resistance of the grass plant, but some Epichloë species produce alkaloids that are toxic for livestock. Therefore, it is important to understand the characteristics of the grass-Epichloë s symbiosis so that the beneficial aspects can be preserved and the toxic effects to livestock can be avoided. Since the 1990s, Chinese researchers have conducted a series of studies on grass-Epichloë symbiosis. In this review, we describe the current state of Epichloë endophyte research in Chinese native grasses. We found that more than 77 species of native grasses in China are associated with Epichloë endophytes. In addition, we review the effects of various Epichloë species on native grass responses to abiotic and biotic stress, phylogeny, and alkaloid production. We provide an overview of the study of Epichloë species on native grasses in China and directions for future research.

Keywords: alkaloid, Chinese native grass, Epichloë endophyte, grass-Epichloë symbiosis, grass stress response, Epichloë phylogeny

\section{INTRODUCTION}

Fungi of the genus Epichloë (Clavicipitaceae, Ascomycota) and their asexual state (Neotyphodium) are common endophytes of cool-season grasses in the subfamily Pooideae (Leuchtmann et al., 2014). Most previous research has indicated that asexual Epichloë species (29 species) are efficiently transmitted through host seeds (vertical transmission) (White et al., 1993; Leuchtmann et al., 2014). However, some recent studies have suggested that strictly asexual Epichloë endophytes are occasionally transmitted horizontally among plants in close proximity via frequent mowing, trampling, and grazing (Cheplick and Faeth, 2009; Iannone et al., 2009; Wiewióra et al., 2015; Saikkonen et al., 2016), and by conidia from epiphytic mycelia (Tadych et al., 2007, 2012; Oberhofer and Leuchtmann, 2014) via splashing water and possibly wind. Sexual Epichloë species (12 species) are transmitted to new hosts with filamentuos ascospores in addition to condia (horizontal transmission) (Leuchtmann et al., 2014; Saikkonen et al., 2016). Leuchtmann et al. (2014) renamed the anamorphs of Neotyphodium as the asexual endophyte genus Epichloë and examined the classification of sexual and asexual Epichloë species and varieties based on $\beta$-tubulin $(t u b B)$ sequences.

Epichloë species often provide numerous benefits to their hosts, such as increased tolerance to drought (Malinowski and Belesky, 2000; Kannadan and Rudgers, 2008; Gundel et al., 2013b), disease resistance (Vignale et al., 2013), resistance to herbivory and parasitism (Bush et al., 1997; Schardl et al., 2007; Gundel et al., 2013a), and enhanced aboveground and belowground vegetative 
and reproductive growth (Marks et al., 1991; Clay and Holah, 1999; Yue et al., 2000; Gundel et al., 2013b; Tadych et al., 2014). Previous studies have confirmed that certain alkaloids play a crucial role in a plant's pasture persistence. For example, lolines and peramine may confer significant toxicity against insect pests (Johnson et al., 1985, 2013; Schardl et al., 2013; Philippe, 2016). However, conflicting results have been reported. When Lolium perenne was grown under conditions of extremely poor nutrient availability, Epichloë festucae var. lolii infection led to a reduced root: shoot ratio and reduced photosynthetic shoot fraction (Cheplick, 2007). Some symbiont combinations, such as Schedonorus arundinaceus with Epichloë coenophiala and Lolium perenne with E. festucae var. lolii, accumulate alkaloids that are toxic to grazing animals (Di Menna et al., 2012; Schardl et al., 2013; Philippe, 2016). On the other hand, sexual Epichloë species could result in "choke disease" in host plants, in which sexual Epichloë species produce stromata that envelop the inflorescences and upper leaf sheaths of flowering culms; this leads to a reduced number of offspring (Lembicz et al., 2010).

Various Epichloë species have been discovered in China, but have not been formally taxonomically described. There are two reasons for this lack of taxonomic data: (i) the limited number of researchers in this field and (ii) insufficient knowledge on the identification and classification of Epichloë species. To address the latter issue, Chinese researchers are establishing collaborations with international institutes. The topic of hybrid occurrence in Chinese Epichloë species is not discussed in-depth in this manuscript because few Epichloë species are confirmed to be of hybrid origin. However, known hybrid species from native grasses appear to have the same two ancestors, for two main reasons. First, researchers have only confirmed some Epichloë species crosses for the Epichloë bromicola $\times$ Epichloë typhina complex. Second, hybrid species are distributed in the same and similar natural and geographic environments. Accordingly, these hybrid species underwent the same hybridization process, but are hosted by different grasses. This topic will be discussed in future reviews when more data are available on hybrid endophytes.

We have built a long-term collaboration with Prof. Christopher L. Schardl from the University of Kentucky and Prof. German Spangenberg from the Australian Academy of Technological Sciences and Engineering. With their help, two kinds of Epichlö̈ endophytes in drunken horse grass were confirmed. The whole genome sequencing of an Epichloë endophyte in Festuca sinensis is near completion. These studies will push Epichloë research to a new level in China. We firmly believe that the research prospects with respect to Epichloë species are bright in our country.

\section{THE DISTRIBUTION AND DIVERSITY OF GRASS-EPICHLOË SYMBIOSIS}

More than 77 species of native grasses in China have been documented as infected with Epichloë species (Nan and Li, 2000; Li et al., 2004, 2006b, 2009, 2012b; Wang et al., 2005; Wei et al., 2006; Moon et al., 2007; Chen et al., 2009; Ji et al., 2009, 2011, 2012; Kang et al., 2009, 2011a; Zhan et al., 2009; Zhang et al.,
2009, 2011a, 2013; Han et al., 2012; Zhu et al., 2013; Card et al., 2014; Leuchtmann et al., 2014). The endophytes have been found in the following grass genera: Achnatherum, Agropyron, Agrostis, Brachypodium, Bromus, Calamagrostis, Cleistogenes, Dactylis, Deschampsia, Elymus, Elytrigia, Eragrostis, Festuca, Hordeum, Koeleria, Leymus, Melica, Poa, Polypopon, Roegneria, and Stipa (Table 1). Among these, many species of Triticeae, Stipeae, and Poeae have been reported as infected and some new Epichloë species have been described from these tribes (Li et al., 2004, 2006b; Wei et al., 2006; Chen et al., 2009; Kang et al., 2009, 2011a; Zhu et al., 2013). To date, nine Epichloë species have been identified from Chinese native grasses (Li et al., 2009; Leuchtmann et al., 2014). Unfortunately, many isolates from Chinese native grasses have not been identified to the species level based on morphology and DNA data (Table 1). For example, an Epichloë endophyte was isolated from Festuca sinensis (Figure 1). We found that this Epichloë endophyte is likely a new species, based on phylogenetic trees constructed using many markers. However, this research is still in progress. We posit that many Epichloë species new to science could be infecting Chinese native grasses.

Most Epichloë species are asexual endophytes without external symptoms in their Chinese host grasses (Leuchtmann et al., 2014), such as E. bromicola, E. gansuensis, E. gansuensis var. inebrians, E. sibirica, and E. sinica. However, Dactylis glomerata (Li et al., 2009), Roegneria kamoji (Li et al., 2006b), and Poa pratensis ssp. pratensis (Kang et al., 2011a) can also be infected with sexual Epichloë species. Although most Chinese Epichloë endophytes are not hybrids, E. sinofestucae (from F. parvigluma) (Chen et al., 2009), E. sinica (from Roegneria spp.) (Kang et al., 2009), E. liyangensis (from P. pratensis ssp. pratensis) (Kang et al., 2011a), and E. sp. (from F. myuros) (Han et al., 2012) are hybrids of E. bromicola and E. typhina (Table 1). E. bromicola is abundant in its host genera Elymus, Hordeum, and Roegneria, including some of the most widely distributed grass species native to China. The hybrid species E. liyangensis, E. sinica, E. sinofestucae, and other Epichloë spp. have a common ancestor, e.g., the sexual E. bromicola from R. kamoji in China.

Interestingly, Epichloë endophytes in natural grasses are morphologically diverse, e.g., the species that infect Achnatherum sibiricum (Wei et al., 2007) and Elymus species (Song et al., 2015b). Ren et al. (2009) isolated 484 Epichloë endophytes from seven populations of $A$. sibiricum in Inner Mongolia, China and detected five morphotypes that also exhibited different magnitudes of inhibition of Rhizoctonia solani, Fusarium oxysporum, Curvularia lunata, Cladosporium cucumerium, and Phomopsis vexans. Researchers have also detected morphological differences along an altitudinal gradient. Epichloë isolates from populations of Elymus above $3000 \mathrm{~m}$ present similar morphological traits, while Epichloë populations below $3000 \mathrm{~m}$ are morphologically variable (Song et al., 2015b). Asexual Epichloë endophytes below $3000 \mathrm{~m}$ tend to grow faster on potato dextrose agar than asexual Epichloë endophytes above $3000 \mathrm{~m}$ (Song et al., 2015b). In addition, a phylogenetic analysis showed that Epichloë endophytes above $3000 \mathrm{~m}$ form a clade, but isolates from regions below $3000 \mathrm{~m}$ belong to several clades (Song et al., 2015b). 
TABLE 1 | Summary of Epichloë endophytes in Chinese native grasses.

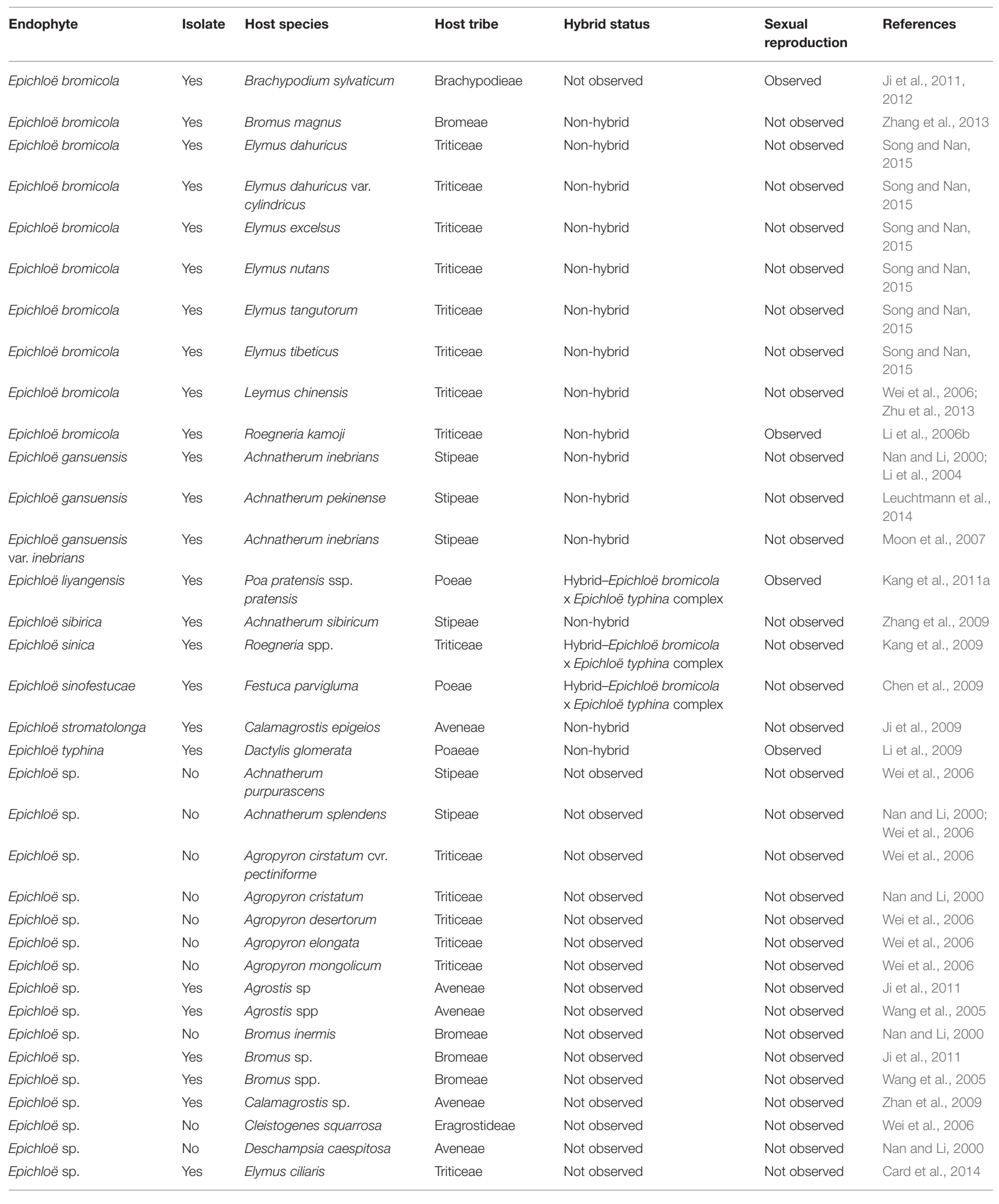


TABLE 1 | Continued

\begin{tabular}{|c|c|c|c|c|c|c|}
\hline Endophyte & Isolate & Host species & Host tribe & Hybrid status & $\begin{array}{l}\text { Sexual } \\
\text { reproduction }\end{array}$ & References \\
\hline Epichloë sp. & No & Elymus cylindricus & Triticeae & Not observed & Not observed & Nan and Li, 2000 \\
\hline Epichloë sp. & Yes & Elymus gmelinii & Triticeae & Not observed & Not observed & Card et al., 2014 \\
\hline Epichloë sp. & Yes & Elymus sp. & Triticeae & Not observed & Not observed & Nan and Li, 2000 \\
\hline Epichloë sp. & No & Elytrigia dahuricus & Triticeae & Not observed & Not observed & Nan and Li, 2000 \\
\hline Epichloë sp. & No & Elytrigia repens & Triticeae & Not observed & Not observed & Wei et al., 2006 \\
\hline Epichloë sp. & No & Elytrigia smitihii & Triticeae & Not observed & Not observed & Wei et al., 2006 \\
\hline Epichloë sp. & Yes & Festuca myuros & Poeae & $\begin{array}{l}\text { Hybrid-Epichloëbromicola x } \\
\text { Epichloë typhina complex }\end{array}$ & Not observed & Han et al., 2012 \\
\hline Epichloë sp. & No & Festuca rubra & Poeae & Not observed & Not observed & Nan and Li, 2000 \\
\hline Epichloë sp. & Yes & Festuca sinensis & Poeae & Not observed & Not observed & Nan and Li, 2000 \\
\hline Epichloë sp. & Yes & Festuca sp. & Poeae & Not observed & Not observed & Ji et al., 2011 \\
\hline Epichloë sp. & Yes & Festuca spp. & Poeae & Not observed & Not observed & Wang et al., 2005 \\
\hline Epichloë sp. & Yes & Hordeum bogdanii & Triticeae & Not observed & Not observed & Nan and Li, 2000 \\
\hline Epichloë sp. & Yes & Hordeum brevisubulatum & Triticeae & Not observed & Not observed & $\begin{array}{l}\text { Nan and Li, 2000; } \\
\text { Wei et al., } 2006\end{array}$ \\
\hline Epichloë sp. & Yes & Hordeum jubatum & Triticeae & Not observed & Not observed & Unpublished data \\
\hline Epichloë sp. & No & Poa palustris & Poeae & Not observed & Not observed & Wei et al., 2006 \\
\hline Epichloë sp. & No & Poa paucifolia & Poeae & Not observed & Not observed & Wei et al., 2006 \\
\hline Epichloë sp. & No & Poa pratensis & Poeae & Not observed & Not observed & Wei et al., 2006 \\
\hline Epichloë sp. & Yes & Poa spp. & Poeae & Not observed & Not observed & Ji et al., 2011 \\
\hline Epichloë sp. & No & Poa sphondylodes & Poeae & Not observed & Not observed & Nan and Li, 2000 \\
\hline Epichloë sp. & No & Poa tibetan & Poeae & Not observed & Not observed & Nan and Li, 2000 \\
\hline Epichloë sp. & No & Polypogon monspeliensis & Agrostideae & Not observed & Not observed & Nan and Li, 2000 \\
\hline Epichloë sp. & Yes & Roegneria canina & Triticeae & Not observed & Not observed & $\begin{array}{l}\text { Zhang et al., } \\
\text { 2011a }\end{array}$ \\
\hline Epichloë sp. & Yes & Roegneria ciliaris & Triticeae & Not observed & Not observed & Wang et al., 2005 \\
\hline Epichloë sp. & Yes & Roegneria hybrida & Triticeae & Not observed & Not observed & Wang et al., 2005 \\
\hline Epichloë sp. & Yes & Roegneria mayebarana & Triticeae & Not observed & Not observed & Wang et al., 2005 \\
\hline Epichloë sp. & No & Roegneria stricta & Triticeae & Not observed & Not observed & Nan and Li, 2000 \\
\hline Epichloë sp. & No & Roegneria turczaninovii & Triticeae & Not observed & Not observed & Wei et al., 2006 \\
\hline Epichloë sp. & No & Stipa grandis & Stipeae & Not observed & Not observed & Wei et al., 2006 \\
\hline Epichloë sp. & No & Stipa purpurea & Stipeae & Not observed & Not observed & Nan and Li, 2000 \\
\hline
\end{tabular}




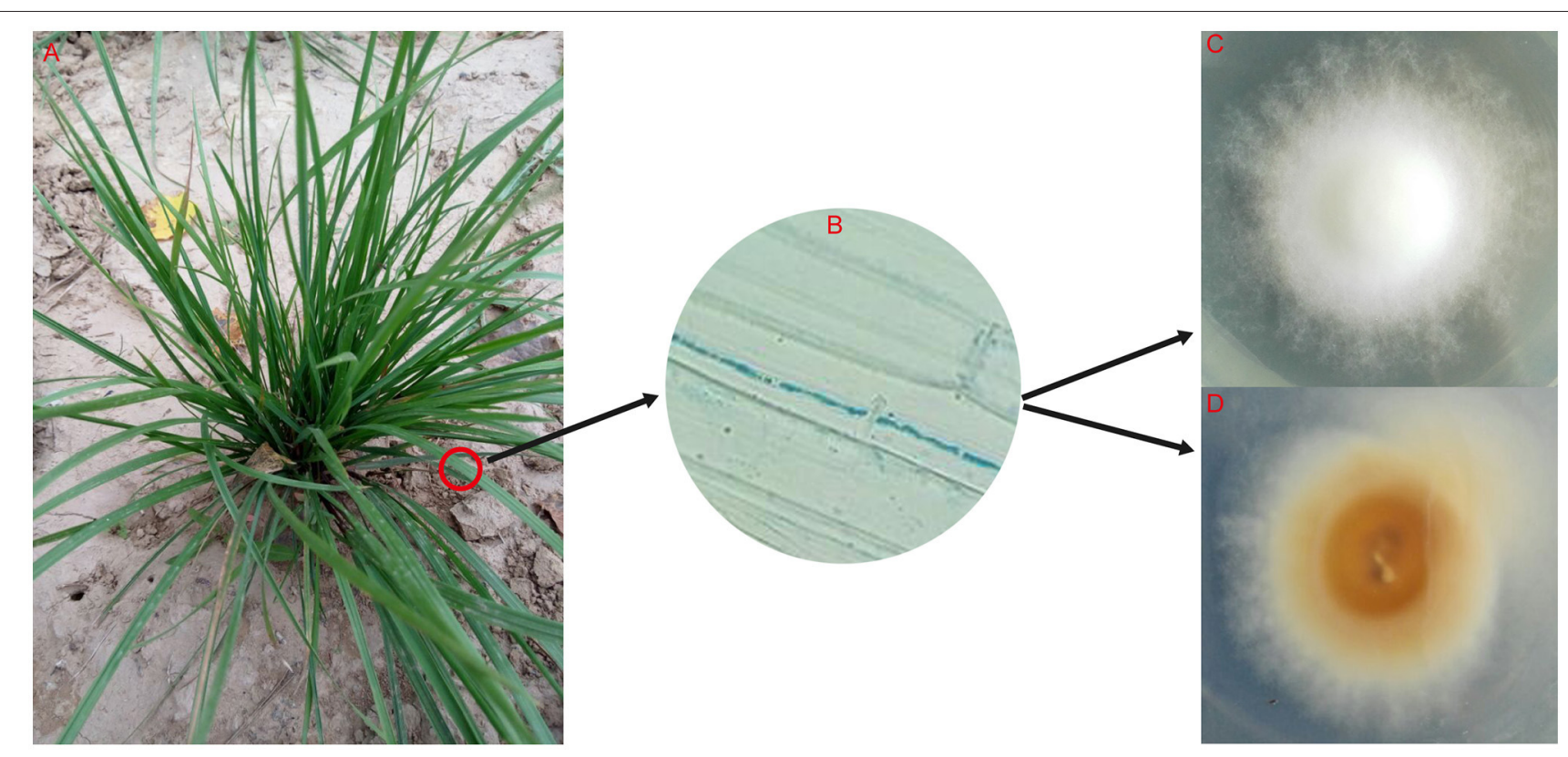

FIGURE 1 | Identification and isolation of Epichloë endophytes in Festuca sinensis. (A) Festuca sinensis. (B) Microscope image of hyphae. Blue line indicates hyphae of Epichloë endophyte detected using the aniline coloring $\left(0.1 \%\right.$ aqueous) method, isolated on potato dextrose agar, and incubated in the dark at $25^{\circ} \mathrm{C}$ for 4 weeks. (C) Obverse of colony. (D) Reverse of colony.

\section{EFFECTS OF EPICHLOË SPECIES ON ABIOTIC AND BIOTIC STRESS IN GRASSES}

\section{Salt Stress}

Plant cells are harmed by salt stress and do not intake sodium as an essential element for their physiology. Although plants have evolved several strategies to adapt to salt stress (Zhu, 2003; Dinneny, 2015), only a few studies have confirmed that Epichloë endophytes can increase salt tolerance in a grass host (Reza Sabzalian and Mirlohi, 2010). When Hordeum brevisubulatum was infected with Epichloë (EI), the grass exhibited significantly increased $\mathrm{N}, \mathrm{P}$, and $\mathrm{K}^{+}$concentrations, which led to an increase in total biomass. The Epichloë infection also reduced $\mathrm{Na}^{+}$ accumulation in the EI plants compared to Epichloë-free plants (EF) (Song et al., 2015d). Based on this work, we inferred that salt tolerance could be further increased in grass-Epichloë symbiosis, which potentially provide a valuable resource for improved salt tolerance in crops.

\section{Drought Stress}

Compared to salt stress, crop plants are inclined to suffer from drought stress (Boyer, 1982). Studies have confirmed Epichloë endophytes play a vital role in increasing drought tolerance in EI grasses (Richardson et al., 1992; Clay and Schardl, 2002; Schardl et al., 2004). A relationship between increased drought tolerance and EI has been well documented in five EI grasses that are native to China. Under drought stress, EI Leymus chinensis had significantly more total biomass than EF L. chinensis, regardless of fertilizer levels (Ren et al., 2014). Peng et al. (2013) found that seed hydropriming treatment is an effective strategy to improve seed germination and plant growth in EI F. sinensis. Epichloë infection also increased the germination of Elymus dahuricus under different osmotic potential pressures, but germination success was variable among populations (Zhang and Nan, 2010). Several studies have shown that Epichloë infection can improve the relative fitness of grasses under drought stress (Faeth, 2002; Faeth et al., 2004; Iannone et al., 2012). Zhang and Nan (2007b) showed that EI E. dahuricus produced more biomass, more tillers, and taller plants under low water treatment, but EI had no influence on plant biomass in the high water treatment. However, in a study of EI A. sibiricum, the addition of fertilizer resulted in greater plant growth, but this advantage decreased under reduced water and/or nutrient availability (Ren et al., 2011). Moreover, Song et al. (2015e) demonstrated that asexual Epichloë endophyte infection can increase resistance to waterlogging stress in $H$. brevisubulatum. The effect of EI on drought tolerance seems to differ among grass species. It remains to be determined whether these effects are caused by the species of infectious Epichloë, the grass species, or other factors.

\section{Other Abiotic Stress}

Epichloë endophytes confer stress tolerance to native grasses in China and play a significant role in the survival of some plants in high-stress environments, such as cadmium (Cd)-contaminated soils and nutrient-depleted soils. Epichloë-infected A. inebrians (Zhang et al., 2010a,b) and E. dahuricus (Zhang et al., 2012a) had higher germination rates, more tillers, longer shoots and roots, and more biomass compared to EF plants in high $\mathrm{Cd}^{2+}$ concentrations. There was no significant difference between 
EI and EF plants under low $\mathrm{Cd}^{2+}$ concentrations, indicating that Epichloë infection was only beneficial to the growth and development of A. inebrians and E. dahuricus exposed to high $\mathrm{Cd}^{2+}$ concentrations.

Studies of nutrient acquisition in EI grasses have focused on the influence of nitrogen $(\mathrm{N})$, since this element is a constituent of alkaloids in infected plants and is also one of the most important limiting resources for plant growth in general (Li et al., 2012a). It has been documented that increased $\mathrm{N}$ availability may change the relative availability of other nutrients, such as phosphorus (P) (Van Der Wouder et al., 1994). Li et al. (2012a) found that $A$. sibiricum-Epichloë associations are conditional on both $\mathrm{N}$ and $\mathrm{P}$ availability, but are more conditional on $\mathrm{N}$ than $\mathrm{P}$. Changes in $\mathrm{N}$ allocation increase the photosynthetic ability of EI plants and also significantly increase their biomass. In addition, the benefits of Epichloë infection decline when nutrient availability decreases (Ren et al., 2011). Epichloë infection tends to reduce overall nitrogen concentration in A. sibiricum leaves, but causes the host to allocate significantly higher fractions of $\mathrm{N}$ to the photosynthetic machinery (Ren et al., 2011). Thus, EI plants have higher photosynthetic $\mathrm{N}$ use efficiency and shoot biomass than that of EF plants when fertilizer is limited (Ren et al., 2014). Song et al. (2015d) confirmed that EI H. brevisubulatum has lower ratios of $\mathrm{C}: \mathrm{N}, \mathrm{C}: \mathrm{P}, \mathrm{Na}^{+}: \mathrm{K}^{+}$and a higher ratio of $\mathrm{N}: \mathrm{P}$ than EF plants under salt stress. According to Jia et al. (2014), the effects of EI on A. sibiricum suggest that the A. sibiricum host genotype has a stronger influence on the response to stress than the influence of Epichloë. They found that Epichloë infection did not positively affect general growth, physiology, or nutrient content of $A$. sibiricum, before or after clipping.

\section{Pest Resistance}

The grass-Epichloë symbiosis provides the grass host protection from herbivorous insects by producing alkaloids in the form of secondary metabolites (García Parisi et al., 2014; Thom et al., 2014). Aphid populations exhibit slow growth when feeding on grass infected with Epichloë species (Hartley and Gange, 2009; Saikkonen et al., 2010). However, Börschig et al. (2014) concluded that the effect of Epichloë endophytes on herbivores is generally weak and depends on the regional environmental context. They posit that more field research is necessary to detect the relative importance of Epichloë endophytes and environmental context on biotic interactions in grasslands (Börschig et al., 2014).

To date, insect resistance has only been reported for L. chinensis-E. bromicola, A. sibiricum-E. sibirica and A. inebrians-E. gansuensis associations in China. Jia et al. (2013) concluded that L. chinensis-E. bromicola and A. sibiricumE. sibirica symbioses could diminish the negative effects of infection by Meloidogyne incognita. The researchers used a 72-h exposure to undiluted culture filtrates of the two endophytes and found $L$. chinensis infected with E. bromicola had an especially strong antagonistic effect on Meloidogyne infection. Similarly, Zhang et al. (2012b) found that A. inebrians infected with E. gansuensis reduced the survival of the aphids Rhopalosiphum padi, Tetranychus cinnabarinus, Oedaleus decorus, and Messor aciculatus under laboratory and field conditions. Additionally, they demonstrate that EI had an anti-herbivore effect on a wide range of arthropod groups (Zhang et al., 2012b).

\section{Pathogen Resistance}

Reports that EI grasses are resistant to diseases and pathogens are limited compared to evidence that EI increases pest resistance. Epichloë endophytes negatively impact the in vitro growth of plant fungal pathogens (White and Cole, 1985; Siegel and Latch, 1991). However, Sabzalian et al. (2012) found that EI tall fescue was not more resistant to powdery mildew (Blumeria graminis) than EF tall fescue. Yue et al. (2000) demonstrated that extracts from a wide range of Epichloë endophytes exhibited various degrees of antifungal activity and the greatest antifungal activity was detected from extracts of E. festucae and E. tembladerae.

Li et al. (2007) confirmed that the fungi Bipolaris sorokiniana, Curvularia lunata, Fusarium acuminatum, and Alternaria alternate cause lesions on detached $A$. inebrians leaves, regardless of their status as EI or EF. When leaves were EF, the number and size of lesions caused by all pathogens were reduced compared to those on EI leaves. In addition, Xia et al. (2015) demonstrated that, in greenhouse conditions, EI reduced the ability of Blumeria graminis to colonize A. inebrians and enhanced the photosynthetic performance of host plants under pathogen stress or ameliorated host plant damage, to some degree (Xia et al., 2016). Zhou et al. (2015b) found that EI F. sinensis produced secondary metabolites that inhibited fungal pathogens, including Alternaria alternata, Bipolaris sorokiniana, Curvularia lunata, and Fusarium acuminatum. They found significant reductions in disease incidence and lesion size on EI detached leaves compared to EF leaves (Zhou et al., 2015b). Song et al. (2015f) found that $E$. bromicola from Elymus tangutorum exhibits antifungal activities against Alternaria alternata, Fusarium avenaceum, Bipolaris sorokiniana, and Curvularia lunata.

\section{MOLECULAR IDENTIFICATION OF CHINESE EPICHLOË SPECIES}

In the past, taxonomic identification of Epichloë endophytes relied on morphological features, e.g., colony morphology, colony growth rate, and spore type and size. Currently, allozyme profiles and molecular methods have been applied to Epichlö̈ research and greatly aid in identification. Recent research combines morphological features and molecular data to identify Epichloë endophytes.

Epichloë endophytes are typically analyzed using $\beta$-tubulin $(t u b B)$ (Tsai et al., 1994), translation elongation factor 1- $\alpha$ (tefA) (Moon et al., 2002), actin (actG) (Moon et al., 2007; Zhang et al., 2009), simple sequence repeats (SSR) (Moon et al., 1999; Schirrmann et al., 2015), amplified fragment length polymorphisms (AFLP) (Karimi et al., 2012), internal transcribed spacers of the nuclear ribosomal RNA (ITS) (Moon et al., 2000), calmodulin M (calM) (McCargo et al., 2014), and so on. The most common markers for taxon identification and determining phylogenetic relationships are $t u b B$, tef $A$, and act $G$ (Clay and Schardl, 2002). These studies have shown that asexual 
Epichloë endophytes evolved from sexual Epichloë species and subsequently lost the ability to sexually reproduce (Moon et al., 2000).

Although new Epichloë endophytes have been identified based on traditional morphology, this method has limitations when determining whether the Epichloë endophytes experienced hybridization events. Fortunately, DNA sequencing can help resolve this problem. To date, all putative Epichloë hybrids contain more than one copy of $t u b B$ and can be detected by allozyme analysis (Moon et al., 2004; Oberhofer and Leuchtmann, 2012; Leuchtmann et al., 2014; Iannone et al., 2015). For example, E. chisosa and E. coenophiala each have three copies (Leuchtmann et al., 2014), indicating they experienced multiple ancient hybridization events or subsequent gene duplication. Oberhofer and Leuchtmann (2012) found four new Epichlö̈ species in Hordelymus europaeus using five enzymes; two were interspecific hybrids and the others were of nonhybrid origin.

Molecular markers can be used to identify new species and to estimate evolutionary relationships with phylogenetic trees. Molecular studies on Chinese Epichloë species have mainly been applied to identify new species. Various Epichloë species, e.g., E. stromatolonga (Li et al., 2006b; Ji et al., 2009), E. sinica (Kang et al., 2009), E. sinofestucae (Chen et al., 2009), E. liyangensis (Kang et al., 2011a), and E. sp. (Han et al., 2012), have been described and exhibit natural symbioses with $R$. kamoji, Calamagrostis epigeios, Roegneria spp., F. parvigluma, $P$. pratensis ssp. pratensis, and F. myuros. These Epichloë species are native to China and were described based on host specificity, morphology, and molecular phylogenetic evidence. Zhang et al. (2009) identified a new Epichloë endophyte, E. sibirica (A. sibiricum), and three morphotypes based on morphological and phylogenetic analyses. They found that its ancestor was probably derived from E. sibirica (Zhang et al., 2009). Zhu et al. (2013) analyzed L. chinensis and found that its Epichloë associate is E. bromicola, which was classified into three morphotypes based on morphological features and phylogenetic analyses of tubB, tef $A$, and $a c t G$ sequences. Additionally, a molecular phylogenetic study showed that E. gansuensis var. inebrians from Chinese $A$. inebrians is a unique and novel non-hybrid species (Moon et al., 2007).

Although some studies have examined the evolutionary relationships among Epichloë species, few have examined the phylogeny or co-evolution of Chinese Epichloë species and hosts. In the southern hemisphere, most asexual Epichloë species are the result of hybridization events between two sexual species (e.g., E. festucae and E. typhina) from the northern hemisphere (Gentile et al., 2005). These studies have looked at the extent of Epichlö gene flow between the Northern and Southern Hemispheres based on molecular data (Moon et al., 2002). Iannone et al. (2009) studied South American Epichloë endophytes from Bromus auleticus and found that E. tembladerae was a hybrid of the Northern E. festucae and E. typhina, but the ancestral E. typhina genotype was distinguished based on $t u b B$ and tefA. Schirrmann et al. (2015) used 15 microsatellites to assess the population structure of sympatric species in the E. typhina complex and found that host specificity and maladaptation of Epichloë hybrids to host grasses may act as reproductive isolation barriers in asexual Epichloë and therefore promote their speciation.

Notably, Kang et al. (2011b) analyzed the asymptomatic symbiosis between Roegneria and E. sinica and found no relationship between phylogeny and morphology in the E. sinica isolates. They concluded that E. sinica is a species complex that resulted from multiple, independent hybridization events (Kang et al., 2011b). In a comparison of genetic diversity in Epichloë species and their host plants, Zhang et al. (2010c) found approximately 4-7-fold greater diversity among Epichlö̈ endophytes than among host plants based on SSR markers. This indicates more gene flow of Epichloë endophytes than hosts. The authors also state that Epichloë infection might confer selective advantages to $A$. sibiricum under certain conditions, which could help to maintain high-EI frequencies, even when their population structure would not suggest selection for EI (Zhang et al., 2010c).

Song et al. found that Epichloë species likely originated in Eurasia, and Epichloë gene flow between the Western and Eastern hemispheres is common based on phylogenetic and network analyses (Song and Nan, 2015; Song et al., 2015a). They suspect that migratory birds or humans might have aided the dispersal of Epichloë endophytes from Eurasia to other continents (Song and Nan, 2015). Furthermore, Song et al. (2015c) analyzed Hordeumendophytes and Elymus-endophytes and found that Chinese Hordeum species likely contain two Epichloë endophyte species. One is also found in North American Elymus species and the other endophyte is found in Chinese Elymus species, indicating that Epichloë endophytes isolated from Chinese Hordeum are not host-specific. They proposed that Epichloë endophytes spread among different grass hosts by plant hybridization, and this could likely transform the hybrid offspring from EF status to EI status (Song et al., 2015c). This needs to be tested in future studies, but it would add further evidence to the hypothesis that asexual Epichloë endophytes are horizontally transmitted (Tadych et al., 2012; Wiewióra et al., 2015). Moreover, molecular phylogenetic studies based on $t u b B$ and tef $A$ intron sequences have confirmed that E. gansuensis infected A. sibiricum and A. inebrians in China, indicating the potential of conidia cultures to mediate horizontal transmission (Li et al., 2015).

\section{ALKALOIDS}

From an agronomic point of view, a negative aspect of the grass-Epichloë symbiosis is that some Epichloë produce ergot and indole-diterpene fungal alkaloids that are highly toxic for livestock (Clay and Schardl, 2002). Variability in the profile and level of alkaloids has allowed researchers to inoculate grass cultivars with selected Epichloë endophytes that are not toxic to livestock and still confer benefits to host plants. This has become a key strategy for breeding drought-, salt-, and pestresistant forage grasses (Gundel et al., 2013b; Johnson et al., 2013). A. inebrians is widely distributed in northern China and is commonly known as drunken horse grass because of its longrecognized toxic and narcotic effects on livestock, especially horses. Additionally, owing to the toxicity to livestock, recent research has shown that $A$. inebrians can protect biodiversity (Yao 
et al., 2015). These toxins are apparently caused by E. gansuensis (Li et al., 2004; Zhang et al., 2014). Epichloë-infected drunken horse grass contains high levels of the ergot alkaloids, ergine, and ergonovine (Miles et al., 1996; Li et al., 2006a). High alkaloid levels have also been confirmed in EI A. inebrians under salt or drought stress, with higher levels of ergonovine than ergine (Zhang et al., 2011b). Cytotoxic effects to animal muscle tissue have been described after the consumption of ergonovine and ergine (Zhang et al., 2014). The EI E. dahuricus only produces the alkaloid peramine. Production is seasonal; the concentration of peramine are highest in October and below detectable levels in June (Zhang and Nan, 2007a). Recently, Zhou et al. (2015a) evaluated the effects of temperature on ergot alkaloid production in three $F$. sinensis ecotypes and found that concentrations of ergine and ergonovine differed considerably in the three endophyte-infected ecotypes. They also found the ecotypes varied in their production of secondary metabolites, the bioprotective alkaloids ergine and ergonovine, in response to short-term cold stress. However, compared to recent research abroad (Schardl et al., 2012), little is known about alkaloid production in Chinese native grasses using molecular methods. We hope to increase research in this area in the future.

\section{CONCLUSIONS AND PERSPECTIVES}

In this review, we briefly summarized progress in Epichloë endophyte research in China in the past 25 years. We found that more than 77 species of native grasses in China were infected with Epichloë species. To date, nine Epichloë species have been identified from Chinese native grasses. Additionally, seven have

\section{REFERENCES}

Börschig, C., Klein, A. M., and Krauss, J. (2014). Effects of grassland management, endophytic fungi and predators on aphid abundance in two distinct regions. J. Plant Ecol. 7, 490-498. doi: 10.1093/jpe/rtt047

Boyer, J. S. (1982). Plant productivity and environment. Science 218, 443-448. doi: 10.1126/science.218.4571.443

Bush, L. P., Wilkinson, H. H., and Schardl, C. L. (1997). Bioprotective alkaloids of grass fungal-endophyte symbioses. Plant Physiol. 114, 1-7.

Card, S. D., Faville, M. J., Simpson, W. R., Johnson, R. D., Voisey, C. R., de Bonth, A. C. M., et al. (2014). Mutualistic fungal endophytes in the Triticeaesurvey and description. FEMS Microbiol. Ecol. 88, 94-106. doi: 10.1111/15746941.12273

Chen, Y. G., Ji, Y. L., Yu, H. S., and Wang, Z. W. (2009). A new Neotyphodium species from Festuca parvigluma Steud. grown in China. Mycologia 101, 681-685. doi: 10.3852/08-181

Cheplick, G. P. (2007). Costs of fungal endophyte infection in Lolium perenne genotypes from Eurasia and North Africa under extreme resource limitation. Environ. Exp. Bot. 60, 202-210. doi: 10.1016/j.envexpbot.2006.10.001

Cheplick, G. P., and Faeth, S. H. (2009). Ecology and Evolution of the GrassEndophyte Symbiosis. New York, NY: Oxford University Press.

Clay, K., and Holah, J. (1999). Fungal endophyte symbiosis and plant diversity in successional fields. Science 285, 1742-1744. doi: 10.1126/science.285.54 34.1742

Clay, K., and Schardl, C. L. (2002). Evolutionary origins and ecological consequences of endophyte symbiosis with grasses. Am. Nat. 160, S99-S127. doi: $10.1086 / 342161$

Di Menna, M. E., Finch, S. C., Popay, A. J., and Smith, B. L. (2012). A review of the Neotyphodium lolii/Lolium perenne symbiosis and its associated effects on been confirmed as new Epichloë endophytes. Epichloë species originated in Eurasia based on the high species diversity in the area (Song and Nan, 2015). Unfortunately, many isolates from Chinese native grasses have not been identified to the species level. Therefore, to apply this precious resource, Chinese research should focus on taxonomical evaluations of Epichloë species from Chinese native grasses. In addition, Chinese studies have extensively examined abiotic and biotic resistance using Epichloë endophytes. However, little is known about Epichloë evolution, functional genomics, and comparative genomics. Nevertheless, we believe that Chinese researchers will intensify their efforts in these areas in the future.

\section{AUTHOR CONTRIBUTIONS}

HS wrote the article. ZN served as the principal investigator, facilitated the project, and assisted in manuscript preparation. QS and CX wrote and revised the paper. XL, XY, WX, YK, PT, and QZ explored literature and modified the article.

\section{ACKNOWLEDGMENTS}

We apologize to colleagues whose work could not be cited owing to space limitations. We sincerely thank Dr. Leopoldo J. Iannone for his critical reviews and comments on an earlier version of this paper. This study was supported by the National Basic Research Program of China (2014CB138702), the National Natural Science Foundation of China (31502001), and the Fundamental Research Funds for the Central Universities (lzujbky-2014-76, lzujbky2014-81).

animal and plant health, with particular emphasis on ryegrass staggers. N. Z. Vet J. 60, 315-328. doi: 10.1080/00480169.2012.697429

Dinneny, J. R. (2015). Traversing organizational scales in plant salt-stress responses. Curr. Opin. Plant Biol. 23, 70-75. doi: 10.1016/j.pbi.2014.10.009

Faeth, S. H. (2002). Are endophytic fungi defensive plant mutualists? Oikos 98 , 25-36. doi: 10.1034/j.1600-0706.2002.980103.x

Faeth, S. H., Helander, M. L., and SaikKonen, K. T. (2004). Asexual Neotyphodium endophytes in a native grass reduce competitive abilities. Ecol. Lett. 7, 304-313. doi: 10.1111/j.1461-0248.2004.00578.x

García Parisi, P. A. G., Grimoldi, A. A., and Omacini, M. (2014). Endophytic fungi of grasses protect other plants from aphid herbivory. Fungal Ecol. 9, 61-64. doi: 10.1016/j.funeco.2014.01.004

Gentile, A., Rossi, M. S., Cabral, D., Craven, K. D., and Schardl, C. L. (2005). Origin, divergence, and phylogeny of Epichloë endophytes of native Argentine grasses. Mol. Phylogenet. Evol. 35, 196-208. doi: 10.1016/j.ympev.2005.01.008

Gundel, P. E., Helander, M., Casas, C., Hamilton, C. E., Faeth, S. H., and Saikkonen, K. (2013a). Neotyphodium fungal endophyte in tall fescue (Schedonorus phoenix): a comparison of three northern European wild populations and the cultivar Kentucky-31. Fungal Divers. 60, 15-24. doi: 10.1007/s13225-01 2-0173-x

Gundel, P. E., Pérez, L. I., Helander, M., and Saikkonen, K. (2013b). Symbiotically modified organisms: non-toxic fungal endophytes in grasses. Trends Plant Sci. 18, 420-427. doi: 10.1016/j.tplants.2013.03.003

Han, K., Ji, Y. L., Wang, Y., and Wang, Z. W. (2012). A Neotyphodium endophyte from Festuca myuros L. in Nanjing, China. Mycology 3, 201-109. doi: 10.1080/21501203.2012.718292

Hartley, S. E., and Gange, A. C. (2009). Impacts of plant symbiotic fungi on insect herbivores: mutualism in a multitrophic context. Annu. Rev. Entomol. 54, 323-342. doi: 10.1146/annurev.ento.54.110807.090614 
Iannone, L. J., Cabral, D., Schardl, C. L., and Rossi, M. S. (2009). Phylogenetic divergenece, morphological and physiological differences distinguish a new Neotyphodium endophyte species in the grass Bromus auleticus from South America. Mycologia 101, 340-351. doi: 10.3852/08-156

Iannone, L. J., Irisarri, J. G. N., McCargo, P. D., Pérez, L. I., and Gundel, P. E. (2015). Occurrence of Epichloë fungal endophytes in the sheep-preferred grass Hordeum comosum from patagonia. J. Arid Environ. 115, 19-26. doi: 10.1016/j.jaridenv.2014.12.008

Iannone, L. J., Novas, M. V., Young, C. A., Battista, J. D. E., and Schardl, C. L. (2012). Endophytes of native grasses from South America: biodiversity and ecology. Fungal Ecol. 5, 357-363. doi: 10.1016/j.funeco.2011.05.007

Jia, C., Ruan, W. B., Zhu, M. J., Ren, A. Z., and Gao, Y. B. (2013). Potential antagnosim of cultivated and wild grass-endophyte associations towards Meloidogyne incognita. Biol. Control 64, 225-230. doi: 10.1016/j.biocontrol.2012.11.008

Jia, T., Ren, A. Z., and Gao, Y. B. (2014). Host genotype overrides endophyte infection effects on growth, physiology, and nutrient content of a native grass, Achnatherum sibiricum. Plant Ecol. 215, 875-887. doi: 10.1007/s11258-0140339-6

Ji, Y. L., Sun, X. H., and Wang, Z. W. (2011). A survey of the gramineous plant endophytes in Huangshan geopark (In Chinese). J. Nanjing Agric. Univ. 34, 147-150.

Ji, Y. L., Sun, X. H., and Wang, Z. W. (2012). "An endophyte obtained from Brachypodium sylvaticum grown in Huangshan," in Proceedings of the 8th international symposium on fungal endophyte of grasses (Lanzhou), 38-40.

Ji, Y. L., Zhan, L. H., Kang, Y., Sun, X. H., Yu, H. S., and Wang, Z. W. (2009). A new stromata-producing Neotyphodium species symbiotic with clonal grass Calamagrostis epigeios (L.) Roth. grown in China. Mycologia 101, 200-205. doi: 10.3852/08-044

Johnson, L. J., de Bonth, A. C. M., Briggs, L. R., Caradus, J. R., Finch, S. C., Fleetwood, D. J., et al. (2013). The exploitation of epichloae endophytes for agricultural benefit. Fungal Divers. 60, 171-188. doi: 10.1007/s13225-01 3-0239-4

Johnson, M. C., Dahlman, D. L., Siegel, M. R., Bush, L. P., Latch, G. C. M., Potter, D. A., et al. (1985). Insect feeding deterrents in endophyte-infected tall fescue. Appl. Environ. Microbiol. 49, 568-571.

Kang, Y., Ji, Y. L., Zhang, C. W., and Wang, Z. W. (2011b). Neotyphodium sinicum, from several Roegneria species throughout China, provides insights into the evolution of asexual endophytes. Symbiosis 54, 37-45. doi: 10.1007/s13199-0110123-5

Kang, Y., Ji, Y., Sun, X., Zhan, L., Li, W., Yu, H., et al. (2009). Taxonomy of Neotyphodium endophytes of Chinese native Roegneria plants. Mycologia 101, 211-219. doi: 10.3852/08-018

Kang, Y., Ji, Y., Zhu, K., Wang, H., Miao, H., and Wang, Z. (2011a). A new Epichloë species with interspecific hybrid origins from Poa pratensis ssp. pratensis in Liyang, China. Mycologia 103, 1341-1350. doi: 10.3852/10-352

Kannadan, S., and Rudgers, J. A. (2008). Endophyte symbiosis benefits a rare grass under low water availability. Funct. Ecol. 22, 706-713. doi: 10.1111/j.13652435.2008.01395.x

Karimi, S., Mirlohi, A., Sabzalian, M. R., Sayed Tabatabaei, B. E., and Sharifnabi, B. (2012). Molecular evidence for Neotyphodium fungal endophyte variation and specificity with host grass species. Mycologia 104, 1281-1290. doi: 10.3852/11316

Lembicz, M., Górzyńska, K., and Leuchtmann, A. (2010). Choke disease caused by Epichloë bromicola in the grass Agropyron repens in Poland. Plant Dis 94, 1372-1372. doi: 10.1094/PDIS-12-09-0810

Leuchtmann, A., Bacon, C. W., Schardl, C. L., White, J. F. Jr., and Tadych, M. (2014). Nomenclatural realignment of Neotyphodium species with genus Epichloë. Mycologia 106, 202-215. doi: 10.3852/13-251

Li, C. J., Gao, J. H., and Nan, Z. B. (2007). Interactions of Neotyphodium gansuense, Achnatherum inebrians, and plant-pathogenic fungi. Mycol. Prog. 111, 1220-1227. doi: 10.1016/j.mycres.2007.08.012

Li, C. J., Wang, Z. F., Chen, N., and Nan, Z. B. (2009). First report of choke disease caused by Epichloë typhina on orchardgrass (Dactylis glomerata) in China. Plant Dis. 93, 673-673. doi: 10.1094/PDIS-93-6-0673B

Li, C., Nan, Z. B., and Schardl, C. L. (2006a). "Levels and temporal variation of ergot alkaloids in endophyte-infected drunken horse grass, Achnatherum inebrians," in China APS, CPS and MSA Joint Meeting Abstracts (Quebec, QC), 203-204.

Li, C., Nan, Z., Paul, V. H., Dapprich, P. D., and Liu, Y. (2004). A new Neotyphodium species symbiotic with drunken horse grass (Achnatherum inebrians) in China. Mycotaxon 90, 141-147.

Li, W., Ji, Y. L., Yu, H. S., and Wang, Z. W. (2006b). A new species of Epichloë symbiotic with Chinese grasses. Mycologia 98, 560-570. doi: 10.3852/mycologia.98.4.560

Li, X., Ren, A., Han, R., Yin, L., Wei, M., and Gao, Y. (2012a). EndophyteMediated effects on the growth and physiology of Achnatherum sibiricum are conditional on both $\mathrm{N}$ and $\mathrm{P}$ availability. PLoS ONE 7:e48010. doi: 10.1371/journal.pone.0048010

Li, X., Zhou, Y., Zhu, M., Qin, J., Ren, A., and Gao, Y. (2015). Stroma-bearing endophyte and its potential horizontal transmission ability in Achnatherum sibiricum. Mycologia 107, 21-31. doi: 10.3852/13-355

Li, X. Z., Li, C. J., and Nan, Z. B. (2012b). "Detection and isolation of endophytes from Melica przewalskyi and Poa tibetica," in Proceedings of the 8th International Symposium on Fungal Endophyte of Grasses (Lanzhou), 42-44.

Malinowski, D. P., and Belesky, D. P. (2000). Adaptations of endophyteinfected cool-season grasses to environmental stresses: mechanisms of drought and mineral stress tolerance. Crop Sci. 40, 923-940. doi: 10.2135/cropsci2000.404923x

Marks, S., Clay, K., and Cheplick, G. P. (1991). Effects of fungal endophytes on interspecific and intraspecific competition in the grasses Festuca arundinacea and Lolium perenne. J. Appl. Ecol. 28, 194-204. doi: 10.2307/2404125

McCargo, P. D., Iannone, L. J., Vignale, M. V., Schardl, C. L., and Rossi, M. S. (2014). Species diversity of Epichloë symbiotic with two grasses feom southern Argentinean Patagonia. Mycologia 106, 339-352. doi: 10.3852/106.2.339

Miles, C. O., Lane, G. A., di Menna, M. E., Garthwaite, I., Piper, E. L., Ball, O. J. P., et al. (1996). High levels of ergonovine and lysergic acid amide in toxic Achnatherum inebrians accompany infection by an Acremonium-like endophytic fungus. J. Agric. Food Chem. 44, 1285-1290. doi: 10.1021/jf950410k

Moon, C. D., Craven, K. D., Leuchtmann, A., Clement, S. L., and Schardl, C. L. (2004). Prevalence of interspecific hybrids amongst asexual fungal endophytes of grasses. Mol. Ecol. 13, 1455-1467. doi: 10.1111/j.1365-294X.2004.02138.x

Moon, C. D., Guillaumin, J. J., Ravel, C., Li, C., Craven, K. D., and Schardl, C. L. (2007). New Neotyphodium endophyte species from the grass tribes Stipeae and Meliceae. Mycologia 99, 895-905. doi: 10.3852/mycologia.99.6.895

Moon, C. D., Miles, C. O., Järlfors, U., and Schardl, C. L. (2002). The evolutionary origins of three new Neotyphodium endophyte species from grasses indigenous to the Southern Hemisphere. Mycologia 94, 694-711. doi: 10.2307/3761720

Moon, C. D., Scott, B., Schardl, C. L., and Christensen, M. J. (2000). The evolutionary origins of Epichloë endophytes from annual ryegrasses. Mycologia 92, 1103-1118. doi: 10.2307/3761478

Moon, C. D., Tapper, B. A., and Scott, B. (1999). Identification of Epichloë endophytes in planata by a microsatellite-based PCR fingerprinting assay with automated analysis. Appl. Environ. Microbiol. 65, 1268-1279.

Nan, Z. B., and Li, C. (2000). "Neotyphodium in native grasses in China and observations on endophyte/host interactions," in Proceedings of the 4th International Neotyphodium/Grass Interactions Symposium University Paderborn, Abteilung Soest, Fachbereich Agrarwirtschaft (Paderborn), 41-49.

Oberhofer, M., and Leuchtmann, A. (2012). Genetic diversity in epichloid endophytes of Hordelymus europaeus suggests repeated host jumps and interspecific hybridizations. Mol. Ecol. 21, 2713-2726. doi: 10.1111/j.1365294X.2012.05459.x

Oberhofer, M., and Leuchtmann, A. (2014). Horizontal transmission, persistence and competition capabilities of Epichloë endophytes in Hordelymus europaeus grass hosts using dual endophyte inocula. Fungal Ecol. 11, 37-49. doi: 10.1016/j.funeco.2014.04.005

Peng, Q., Li, C., Song, M., and Nan, Z. (2013). Effects of seed hydropriming on growth of Festuca sinensis infected with Neotyphodium endophyte. Fungal Ecol. 6, 83-91. doi: 10.1016/j.funeco.2012.08.001

Philippe, G. (2016). Lolitrem, B., and indole diterpene alkaloids produced by endophytic fungi of the genus Epichloë and their toxic effects in livestock. Toxins (Basel). 8:47. doi: 10.3390/toxins 8020047

Ren, A., Wei, M., Yin, L., Wu, L., Zhou, Y., Li, X., et al. (2014). Benefits of a fungal endophyte in Leymus chinensis depend more on 
water than on nutrient availability. Environ. Exp. Bot. 108, 71-78. doi: 10.1016/j.envexpbot.2013.11.019

Ren, A. Z., Li, X., Han, R., Yin, L. J., Wei, M. Y., and Gao, Y. B. (2011). Benefits of a symbiotic association with endophytic fungi are subject to water and nutrient availability in Achnatherum sibiricum. Plant Soil 346, 363-373. doi: 10.1007/s11104-011-0824-9

Ren, A. Z., Wang, Y. H., and Gao, Y. B. (2009). Difference in antifungal activity of morphotypes of clavicipitaceous endophytes within and between species. Acta Ecol. Sin. 29, 227-231. doi: 10.1016/j.chnaes.2009.08.005

Reza Sabzalian, M., and Mirlohi, A. (2010). Neotyphodium endophytes trigger salt resistance in tall and meadow fescues. J. Plant Nutr. Soil Sci. 173, 952-957. doi: 10.1002/jpln.200900345

Richardson, M. D., Chapman, G. W. J., Hoveland, C. S., and Bacon, C. W. (1992). Sugar alcohols in endophyte-infected tall fescue under drought. Crop Sci. 32, 1060-1061. doi: 10.2135/cropsci1992.0011183X003200040045x

Sabzalian, M. R., Mirlohi, A., and Sharifnabi, B. (2012). Reaction to powde ry mildew fungus, Blumer ia graminis in endophyte-infected and endophytefree tall and meadow fescues. Australas. Plant Path. 41, 565-572. doi: 10.1007/s13313-012-0147-1

Saikkonen, K., Saari, S., and Helander, M. (2010). Defensive mutualism between plants and endophytic fungi? Fungal Divers. 41, 101-113. doi: 10.1007/s13225010-0023-7

Saikkonen, K., Young, C. A., Helander, M., and Schardl, C. L. (2016). Endophytic Epichloë species and their grass hosts: from evolution to applications. Plant Mol. Biol. 90, 665-675. doi: 10.1007/s11103-015-0399-6

Schardl, C. L., Grossman, R. B., Nagabhyru, P., Faulkner, J. R., and Mallik, U. P. (2007). Loline alkaloids: currencies of mutualism. Phytochemistry 68, 980-996. doi: 10.1016/j.phytochem.2007.01.010

Schardl, C. L., Leuchtmann, A., and Spiering, M. J. (2004). Symbioses of grasses with seedborne fungal endophytes. Annu. Rev. Plant Biol. 55, 315-340. doi: 10.1146/annurev.arplant.55.031903.141735

Schardl, C. L., Young, C. A., Faulkner, J. R., Florea, S., and Pan, J. (2012). Chemotypic diversity of epichloae, fungal symbionts of grasses. Fungal Ecol. 5, 331-344. doi: 10.1016/j.funeco.2011.04.005

Schardl, C. L., Young, C. A., Pan, J., Florea, S., Takach, J. E., Panaccione, D. G., et al. (2013). Currencies of mutualisms: sources of alkaloid genes in vertically transmitted epichloae. Toxins 5, 1064-1088. doi: 10.3390/toxins5061064

Schirrmann, M. K., Zoller, S., Fior, S., and Leuchtmann, A. (2015). Genetic evidence for reproductive isolation among sympatric Epichloë endophytes as inferred from newly developed microsatellite markers. Microb. Ecol. 70, 51-60. doi: 10.1007/s00248-014-0556-5

Siegel, M. R., and Latch, G. C. M. (1991). Expression of antifungal activity in agar culture by isolates of grass endophytes. Mycologia 83, 529-537. doi: $10.2307 / 3760368$

Song, H., Li, X., Bao, G., Song, Q., and P. T., Nan, Z. (2015a). Phylogeny of Neotyphodium endophyte from western Chinese Elymus species based on act sequences (In Chinese). Acta Microbiol. Sin. 55, 273-281. doi: 10.13343/j.cnki.wsxb.20140268

Song, H., and Nan, Z. (2015). Origin, divergence, and phylogeny of asexual Epichloë endophyte in Elymus species from western China. PLoS ONE 10:e0127096. doi: 10.1371/journal.pone.0127096

Song, H., Nan, Z., and Tian, P. (2015b). Cultural characteristic of asexual endophytes from Elymus species in northwest China (In Chinese). Acta Prataculturae Sin. 24, 89-95. doi: 10.11686/cyxb2014411

Song, H., Song, Q. Y., Li, X. Z., and Nan, Z. B. (2015c). Are Epichloë endophytes specific to Elymus grass hosts? Genet. Mol. Res. 14, 17463-17471. doi: 10.4238/2015.December.21.17

Song, M., Chai, Q., Li, X., Yao, X., Li, C., Christensen, M. J., et al. (2015d). An asexual Epichloë endophyte modifies the nutrient stoichiometry of wild barley (Hordeum brevisubulatum) under sal t stress. Plant Soil 387, 153-165. doi: 10.1007/s11104-014-2289-0

Song, M., Li, X., Saikkonen, K., Li, C., and Nan, Z. (2015e). An asexual Epichloë endophyte enhances waterlogging tolerance of Hordeum brevisubulatum. Fungal Ecol. 13, 44-52. doi: 10.1016/j.funeco.2014.07.004

Song, Q. Y., Nan, Z. B., Gao, K., Song, H., Tian, P., Zhang, X. X., et al. (2015f). Antifungal, phytotoxic, and cytotoxic activities of metabolites from Epichloë bromicola, a fungus obtained from Elymus tangutorum grass. J. Agric. Food Chem. 63, 8787-8792. doi: 10.1021/acs.jafc.5b04260
Tadych, M., Ambrose, K. V., Bergen, M. S., Belanger, F. C., and White, J. F. Jr. (2012). Taxonomic placement of Epichloë poae sp. nov. and horizontal dissemination to seedling via conidia. Fungal Divers. 54, 117-131. doi: 10.1007/s13225-012-0170-0

Tadych, M., Bergen, M., Dugan, F. M., and White, J. F. Jr. (2007). Evaluation of the potential role of water in spread of conidia of the Neotyphodium endophyte of Poa ampla. Mycol. Res. 111, 466-472. doi: 10.1016/j.mycres.2007.02.002

Tadych, M., Bergen, M. S., and White, J. F. Jr. (2014). Epichloë spp. associated with grasses: new insights on life cycles, dissemination and evolution. Mycologia 106, 181-201. doi: 10.3852/106.2.181

Thom, E. R., Popay, A. J., Waugh, C. D., and Minneé, E. M. K. (2014). Impact of novel endophytes in perennial ryegrass on herbage production and insect pests from pastures under dairy cow grazing in northern New Zealand. Grass Forage Sci. 69, 191-204. doi: 10.1111/gfs.12040

Tsai, H. F., Liu, J. S., Staben, C., Christensen, M. J., Latch, G. C. M., Siegel, M. R., et al. (1994). Evolutionary diversification of fungal endophytes of tall fescue grass by hybridization with Epichloë species. Proc. Natl. Acad. Sci. U.S.A. 91, 2542-2546.

Van Der Wouder, B. J., Pegtel, D. M., and Bakker, J. P. (1994). Nutrient limitation after longterm nitrogen-fertilizer application in cut grasslands. J. Appl. Ecol. 31, 405-412. doi: 10.2307/2404438

Vignale, M. V., Astiz-Gassó, M. M., Novas, M. V., and Iannone, L. J. (2013). Epichloid endophytes confer resistance to the smut Ustilago bullata in the wild grass Bromus auleticus (Trin.). Biol. Control 67, 1-7. doi: 10.1016/j.biocontrol.2013.06.002

Wang, Z. W., Wang, S. M., Ji, Y. L., Zhao, M. W., and Yu, H. S. (2005). Plant endophyte research 6: detection and distribution of endophytic fungus in gramineous plants in saline-alkali area in Dongying (In Chinese). Pratacultural Sci. 22, 60-64.

Wei, Y. K., Gao, Y. B., Xu, H., Su, D., Zhang, X., Wang, Y. H., et al. (2006). Occurrence of endophytes in grasses native to northern China. Grass Forage Sci. 61, 422-429. doi: 10.1111/j.1365-2494.2006.00551.x

Wei, Y. K., Gao, Y. B., Zhang, X., Su, D., Wang, Y. H., Xu, H., et al. (2007). Distribution and diversity of Epichloë/Neotyphodium fungal endophytes from different populations of Achnatherum sibiricum (Poaceae) in the Inner Mongolia Steppe, China. Fungal Divers. 24, 329-345.

White, J. F. Jr., and Cole, G. T. (1985). Endophyte-host associations in forage grasses. III. In vitro inhibition of fungi by Acremonium coenophialum. Mycologia 77, 487-489. doi: 10.2307/3793206

White, J. F. Jr., Morgan-Jones, G., and Morrow, A. C. (1993). Taxonomy, life cycle, reproduction and detection of Acremonium endophytes. Agric. Ecosyst. Environ. 44, 13-37. doi: 10.1016/0167-8809(93)90037-P

Wiewióra, B., Żurek, G., and Pańka, D. (2015). Is the vertical transmission of Neotyphodium lolii in perennial ryegrass the only possible way to the spread of endophytes? PLOS ONE 10:e0117231. doi: 10.1371/journal.pone.01 17231

Xia, C., Li, N., Zhang, X., Feng, Y., Christensen, M. J., and Nan, Z. (2016). An Epichloë endophyte improves photosynthesis ability and dry matter production of its host Achnatherum inebrians infected by Blumeria graminis under various soil water conditions. Fungal Ecol. 22, 26-34. doi: 10.1016/j.funeco.2016.04.002

Xia, C., Zhang, X., Christensen, M. J., Nan, Z., and Li, C. (2015). Epichloë endophyte affects the ability of powdery mildew (Blumeria graminis) to colonise drunken horse grass (Achnatherum inebrians). Fungal Ecol. 16, 26-33. doi: 10.1016/j.funeco.2015.02.003

Yao, X., Christensen, M. J., Bao, G., Zhang, C., Li, X., Li, C., et al. (2015). A toxic endophyte-infected grass helps reverse degradation and loss of biodiversity of over-grazed grasslands in northwest China. Sci. Rep. 5:18527. doi: $10.1038 /$ srep 18527

Yue, Q., Miller, C. J., White, J. F. Jr., and Richardson, D. (2000). Isolation and characterisation of fungal inhibiyors from Epichloë festucae. J. Agric. Food Chem. 48, 4687-4692. doi: 10.1021/jf990685q

Zhan, L. H., Ji, Y. L., Yu, H. S., Kang, Y., Sun, X. H., and Wang, Z. W. (2009). Grass endophyte researches 8 - Distribution and morphological characteristics of Neotyphodium sp. grown in Calamagrostis spp. in China (In Chinese). Pratacult. Sci. 26, 13-18.

Zhang, C. W., Ji, Y. L., Yang, S. L., Kang, Y., and Wang, Z. W. (2011a). Isolation and identification of a fungal endophyte obtained from Roegneria canina (L.) Nevski grown in Jilin, China (In Chinese). J. Nanjing Agric. Univ. 34, 78-84 
Zhang, H. X., Ji, Y. L., Xing, Z. Q., and Wang, Z. W. (2013). Grass endophyte researches 17: biological properties of Bromus magnus-epichloid endophyte symbiosis grown in Huangshan (In Chinese). J. Nanjing Agric. Univ. 36, 59-64. doi: 10.7685/j.issn.1000-2030.2013.05.010

Zhang, X., Fan, X., Li, C., and Nan, Z. (2010a). Effects of cadmium stress on seed germination, seedling growth and antioxidative enzymes in Achnatherum inebrians plants infected with a Neotyphodium endophyte. Plant Growth Regul. 60, 91-97. doi: 10.1007/s10725-009-9422-8

Zhang, X., Li, C., and Nan, Z. (2010b). Effects of cadmium stress on growth and anti-oxidative systems in Achnatherum inebrians symbiotic with Neotyphodium gansuense. J. Hazard. Mater. 175, 703-709. doi: 10.1016/j.jhazmat.2009. 10.066

Zhang, X., Nan, Z., Li, C., and Gao, K. (2014). Cytotoxic effect of ergot alkaloids in Achnatherum inebrians infected by the Neotyphodium gansuense endophyte. J. Agric. Food Chem. 62, 7419-7422. doi: 10.1021/jf502264j

Zhang, X., Ren, A. Z., Ci, H., and Gao, Y. (2010c). Genetic diversity and structure of Neotyphodium species and their host Achnatherum sibiricum in a natural grass-endophyte system. Microb. Ecol. 59, 744-756. doi: 10.1007/s00248-0109652-3

Zhang, X., Ren, A.-Z., Wei, Y.-K., Lin, F., Li, C., Liu, Z.-J., et al. (2009). Taxonomy, diversity and origins of symbiotic endophytes of Achnatherum sibiricum in the Inner Mongolia Steppe of China. FEMS Microbiol. Lett. 301, 12-20. doi: 10.1111/j.1574-6968.2009.01789.x

Zhang, X. X., Li, C. J., and Nan, Z. B. (2011b). Effects of salt and drought stress on alkaloid production in endophyte-infected drunken horse grass (Achnatherum inebrians). Biochem. Syst. Ecol. 39, 471-476. doi: 10.1016/j.bse.2011.06.016

Zhang, X. X., Li, C. J., and Nan, Z. B. (2012a). Effects of cadmium stress on seed germination and seedling growth of Elymus dahuricus infected with the Neotyphodium endophyte. Sci. China Life Sci. 55, 793-799. doi: 10.1007/s11427012-4359-y

Zhang, X. X., Li, C. J., Nan, Z. B., and Matthew, C. (2012b). Neotyphodium endophyte increases Achnatherum inebrians (drunken horse grass) resistance to herbivores and seed predators. Weed Res. 52, 70-78. doi: 10.1111/j.13653180.2011.00887.x
Zhang, Y., and Nan, Z. (2007a). Distribution of Epichloë endophytes in Chinese populations of Elymus dahuricus and variation in peramine levels. Symbiosis 43, 13-19.

Zhang, Y. P., and Nan, Z. B. (2007b). Growth and anti-oxidative systems changes in Elymus dahuricus is affected by Neotyphodium endophyte under contrasting water availability. J. Agron. Crop Sci. 193, 377-386. doi: 10.1111/j.1439037X.2007.00279.x

Zhang, Y. P., and Nan, Z. B. (2010). Germination and seedling anti-oxidative enzymes of endophyte-infected populations of Elymus dahuricus under osmotic stress. Seed Sci. Thchnol. 38, 522-527. doi: 10.15258/sst.2010.38.2.25

Zhou, L., Li, C., Zhang, X., Johnson, R., Bao, G., Yao, X., et al. (2015a). Effects of cold shocked Epichloë infected Festuca sinensis on ergot alkaloid accumulation. Fungal Ecol. 14, 99-104. doi: 10.1016/j.funeco.2014.12.006

Zhou, L. Y., Zhang, X. X., Li, C. J., Christensen, M. J., and Nan, Z. B. (2015b). Antifungal activity and phytochemical investigation of the asexual endophyte of Epichloë sp. from Festuca sinensis. Sci. China Life Sci. 58, 821-826. doi: 10.1007/s11427-015-4845-0

Zhu, J. K. (2003). Regulation of ion homeostasis under salt stress. Curr. Opin. Plant Biol. 6, 441-445. doi: 10.1016/S1369-5266(03)00085-2

Zhu, M. J., Ren, A. Z., Wen, W., and Gao, Y. B. (2013). Diversity and taxonomy of endophytes from Leymus chinensis in the Inner Mongolia steppe of China. FEMS Microbiol. Lett. 340, 135-145. doi: 10.1111/1574-6968.12083

Conflict of Interest Statement: The authors declare that the research was conducted in the absence of any commercial or financial relationships that could be construed as a potential conflict of interest.

Copyright (c) 2016 Song, Nan, Song, Xia, Li, Yao, Xu, Kuang, Tian and Zhang. This is an open-access article distributed under the terms of the Creative Commons Attribution License (CC BY). The use, distribution or reproduction in other forums is permitted, provided the original author(s) or licensor are credited and that the original publication in this journal is cited, in accordance with accepted academic practice. No use, distribution or reproduction is permitted which does not comply with these terms. 